\title{
Exploring the Association and Dissociation Between Lectures and Practicums in the Process of Learning Experience in Psychiatric and Mental Health Nursing Education: a Qualitative Study in Japan
}

Ryo Odachi ( $\square$ odachi@sahs.med.osaka-u.ac.jp )

Osaka University

Hironori Yada

Yamaguchi University

Keiichiro Adachi

Yamaguchi University

\section{Research Article}

Keywords: Psychiatric and mental health nursing, Nursing education, Theory and practice gap, Clinical practice, Class

Posted Date: March 24th, 2021

DOI: https://doi.org/10.21203/rs.3.rs-318143/v1

License: (c) (i) This work is licensed under a Creative Commons Attribution 4.0 International License. Read Full License 


\section{Abstract}

Objective: This study aimed to clarify the process of students' experience of learning to identify association and dissociation between lectures and practicums in psychiatric and mental health nursing (PMHN) education at a university.

Methods: An interview survey of 21 students from a regional national university in Japan was conducted, and the interview data were analyzed with a modified grounded theory approach.

Results: The analysis identified 12 categories and 32 concepts regarding the process of learning experience in PMHN among university nursing students. Through lectures, the students accomplished "self-developmental knowledge retention" or "acquisition of superficial knowledge about PMHN" toward "formation of learning attitude based on life experience." The outcomes of lectures significantly affected practicums; the former possibly resulted in "nondiscovery of significance of practicums;" however, the latter possibly approached "developmental self-learning."

Discussion: The association between students' interests based on life experience and contents of lectures affected practicums, and the lecture design readily imaginable from students' experience was desirable. Practicums must be built on teaching strategies that make students aware of the particularity of communication.

\section{Background}

The aim of nursing education in universities in Japan is to nurture practitioners, researchers, and educators of nursing. The basis of these aims is to nurture nurses as professionals (1). In particular, the major function of nursing education at universities in Japan is currently to nurture nurses because $>80 \%$ of graduates of undergraduate nursing programs become clinical nurses (2). To achieve the aim of nurturing nurses, clinical training is an important means for the experience of learning of nursing skills and nursing development in actual patients. The basis of this clinical training is on-campus lectures and exercises, and the subjects with this process of "from lectures to practicums" are primary elements of the curriculum. Therefore, clinical training has an aspect as outcome of lectures and exercises, and teachers are required to design lectures and exercises while this outcome is remembered. However, discrepancies between knowledge taught through lectures (theory) and practice acquired through practicums, described as "theory-practice gaps," have been reported (3-6). What is behind the theory-practice gap studies is the transition of education from nursing colleges to universities where students acquire a greater wealth of knowledge; however, these studies have placed additional stress on approaches to improve lectures and practicums in terms of how to convey the practice in a clinical setting (3). Regarding the emphasis on clinical practice, there are criticisms because it requires apprenticeship training, e.g., Honda stated that while vocational education must equip students with the ability to learn how to "adapt" to the real world, it provides them with an opportunity to learn how to "resist" it (7). Both academic expertise and practice skills in clinical setting are essential in nursing education and continued examination is necessary as to how to balance these two subjects in education. For this purpose and because the nursing education system in one country is quite different from that in another country, it is meaningful to explore theory-practice gaps and link between lectures and practicums in Japan. However, studies on the theory-practice gaps in Japan are limited to only a small number focusing on fundamental nursing by Kagawa et al. (8,9).

Compared with other with areas, theory-practice gaps and association between lectures and practicums in psychiatric and mental health nursing (PMHN) are deducible to be unique in the following points. Core skills in PMHN are related to communication (10). Communication-related skills are situationdependent; thus, they have multiple variations and are abstract. Certain studies documented that uniquely difficulties are associated with the transmission of knowledge and practice about communication-related skills, e.g., lectures have been reported to emphasize on the way of thinking rather than how to practice, thus having differences from practice and leaving students unconfident in the proper use communication-related skills $(11,12)$. It is impossible to visualize or measure certain aspects of PMHN skills (10), and many mental diseases cannot be diagnosed based on laboratory results and diagnostic imaging data. Such facts make PMHN skills difficult for students to understand. Another big limitation for students is stigma. Stigmatization remains a problem associated with mental illness; it has been reported that people possibly feel anxiety and fear about those with mental illness and how to treat them (13). Nursing students are no exception; nursing students before practicums have been reported to have similar stigmas to the general public (12,14). Therefore, nursing students before PMHN practicums are possibly tense with anxiety and fear from stigma for patients; this is another unique point setting PMHN practicums apart from other practicums. An approach with qualitative research is effective for such unknown and complex events. Qualitative research uses open research methods for the complexity to study complex subjects (15). Nursing education is a phenomenon in which complex interactions are intertwined such as transition of the educational field from classroom to clinical setting and the presence of various instructors. Learning experience, which is the subject of this study, is the process of acquiring knowledge and then putting it into practice. A modified grounded theory approach (M-GTA), developed by Kinoshita, is reportedly suitable for such phenomena that progress in steps. Therefore, this study aimed to clarify association between lectures and practicums and gap-related learning experience in PMHN using M-GTA in nursing university students.

\section{Methods}

Design

This qualitative study used M-GTA, which is the most popular analysis method using GTA in Japan (16). M-GTA was developed by Kinoshita and generally adheres to the tenets of the original grounded theory approach (GTA) such as a constant comparative method and grounded data (17). It is considered "modified" because it clarifies the method of segmenting data during analysis. Specifically, it posits that data segmenting is based on two concepts: the analysis theme and the individuals who are the focus of the analysis. In GTA, the aim of segmentation is to maintain a distance between obtained data and researchers to avoid being influenced by participants' perspectives. However, M-GTA asks a researcher to understand the participants' perspective;

Page $2 / 11$ 
specifically, M-GTA requires a qualitative analysis to interpret meaning. Therefore, in M-GTA, one does not use segmented data by predefined units such as a word or a sentence, allowing for a deeper interpretation of meaning (18).

Setting and participants

There are sampling strategy discrepancies between the GTA and M-GTA, e.g., the strategy of the GTA is to collect and analyze data in parallel and its process proceeds by comparing participants. However, the strategy of the M-GTA is to collect data for a specific group; then, the researchers analyze this "base data." After this process, researchers collect additional specific data as required (18).

This study recruited participants from a national university in Western Japan who had agreed to cooperate. In the curriculum of this university, students studied in classroom or training room primarily by sophomore and they had first clinical practice in fundamental nursing at the end of the year. Junior participants primarily learned in certain clinical practices, which were adult nursing, maternal nursing and PMHN. Senior participants had clinical practice for child health nursing, gerontological nursing, home care nursing and public health nursing. The PMHN clinical practice was a two-week program. In the first week, student learned in hospital's psychiatric units and they had a patient in charge. Moreover, they learned at certain facilities for people with mental illness in community in another week. These facilities had each role, such as supporting employments and works, counseling for daily lives and providing the place in the daytime. Most participants were junior who had experienced all clinical practices in the year. However, a few students were sophomore or senior. The reason of this recruitment was for comparison, which would be clarifying characteristics and learning process of clinical practices in PMHN on the junior. The participants of sophomore were only students who experienced fundamental nursing clinical practice in a psychiatric unit. Firstly, in this study, junior participants were recruited after a lecture conducted at about three months later all junior's clinical practice finished. Furthermore, snowball sampling was used. Sophomore's and senior's participants were recruited by snowball sampling. Although this study was mainly conducted joint interview, one-to-one interview was conducted when a participant hoped.

Data collection

The data were collected via semi-structured interviews conducted from October 2017 to March 2018. In this study, joint interview was conducted. Joint interview is one of the interviews involving two interviewees for one interviewer. It is because that participants were students who might hesitate to tell the interviewer the negative or critical aspects of educational programs. The advantages of joint interview are interaction between interviewees that would promote to freely talk and improve the trustworthiness of the study $(19,20)$. Each participant was interviewed once for $60-90$ min by an interviewer in a private room and ensured that their comment would remain anonymous. The interviewer proceeded through the interview using an interview guide. The interviewer took notes about participants' voices and reactions. Moreover, the interviewer asked participants additional questions (e.g., "why?" and "how?") to obtain more detailed information. Although the researcher used the interview guide to enhance efficiency and equity, the participants were encouraged to freely talk. The interview guide was created through certain pre-interviews. The researchers began each interview by telling the participants, "We would like to know about your experience of clinical practice in PMHN. Please tell us about your experiences of particularly impressive event in it." The major questions covered in the interview guide were about student's thought and behavior in clinical practice and classroom lecture. For example, "What kind of knowledge did you obtain and what did you think about you had obtained?", What did you do and think in clinical practice?" Moreover, the questions were involved such as "Please tell me the gap between clinical practice and lecture that you experienced" and "Please tell me the link between clinical practice and lecture that you experienced." Furthermore, the interviewer actively asked out-of-school experience behind the participants' narrative. For promoting participants recall, the interviewer asked participants to bring their notebook or material using at their clinical practice or lecture in the interview. All interviews' datum were recorded with participants' consent and transcribed verbatim later.

Analysis

First, the researchers decided the analysis theme to determine the rage of using data about actions and emotions, thought of the students for analysis; then, the researchers determined the person to focus on for analysis to determine the person as the subject doing the analytical theme. The former comprised "the experience of learning PHMN." The latter comprised "nursing students learning PMHN in the university."

In M-GTA, the minimum analytical unit is the concept. Each concept is derived from several pieces of data known as variations, which are collected along the analysis theme and transcribed verbatim and repeatedly analyzed to obtain their meaning. When a concept emerged, similar or antithetical data related to the concept were examined to prevent arbitrary interpretation. The relationships between concepts were examined and categories were deduced from related concepts. Then, the relationships between the categories were examined, and the data comparison and analysis were repeated. Finally, the researcher wrote "storyline," which was a simple explanation mainly comprising categories as the result of analysis. Figure about result were written based on storyline.

Rigor

The criteria of trustworthiness, credibility, dependability, and transferability were used to ensure rigor (21). All recording data were transcribed verbatim and researchers shared them. The first author was the only one involved in the coding process; however, the analysis sessions were conducted in conjunction with the remaining researchers. The discussions were held until all researchers reached agreement on the codes. The researchers conducted memberchecking, which was discussion with researchers and informant together about the results of our analysis to obtain their feedback.

\section{Results}


Note that 21 nursing students were recruited and 12 interviews were conducted, and two interviews were one-to-one. The mean of interview time was 66 min (range $=45-111$ ). Participants were 17 female and 4 male students. The mean of age were 21.1 years (range: $20-26$ years) and 2 were second year students, 14 were third year students, 3 were fourth year students.

The categories and concepts are presented in Table 1, and the relationships between categories are illustrated in Figure 1. Note that four categories were related to experiences in classrooms and other seven categories were about clinical practice. The storyline and the explanations about each category were written as follows.

Storyline

Nursing students' learning experience processes over the course of PMHN in lectures reached positive and active "self-developmental knowledge acquisition" or passive "acquisition of superficial knowledge about PMHN" through "formation of learning attitude based on life experience." Moreover, students' passive learning was promoted by the "encounter with ambiguity in PMHN," and there was a tendency toward polarized learning outcomes. In practicums, students initially had "a feeling of unrest evoked by the start of practicum," but "partial adaptation with practicum resources" solved students' tension. After students transiently had "Facing the reconsideration of students' own communication skills" albeit to a varying extent, they obtained success by "redefining communication." However, other results had considerable effects on learning outcomes of lectures. Students whose result of lectures was passive learning outcomes had "confusion in knowledge about people with mental illness" and "difficulty in understanding practical skills in PMHN;" "non-discovery of significance of practicums" was prone to become foreground as a learning experience in these students. The other group of students was able to readily identify meaning in practicums as a learning experience characterized by positive and active "developmental self-learning."

Table 1. Categories and concepts 


\begin{tabular}{|c|c|}
\hline \multirow[t]{4}{*}{ Formation of learning attitude based on life experience } & evoking interest with visual teaching materials \\
\hline & formation of learning motivation dependent on individual's interest \\
\hline & motivation based on everyday interest \\
\hline & motivation based on experience with close relationship with mental illness \\
\hline \multirow[t]{2}{*}{ Encounters with ambiguity in PMHN } & anxiety when no answer is presented \\
\hline & difficulty in developing concrete image of lecture knowledge \\
\hline \multirow[t]{2}{*}{ Self-developmental knowledge acquistion } & updating existing knowledge with lecture knowledge \\
\hline & promotion of understanding through development of images \\
\hline \multirow[t]{3}{*}{ Acquisition of superficial knowledge about PMNH } & acquisition of simplified expertise \\
\hline & increased prejudice because of lecture knowledge \\
\hline & acquisition of knowledge for written examination \\
\hline \multirow[t]{3}{*}{ A feeling of unrest evoked by the start of practicum } & a feeling of anxiety from negative image of psychiatric wards \\
\hline & a feeling of tension evoked by entering a psychiatric ward \\
\hline & a mental burden from patient's narrative for understanding a patient \\
\hline \multirow[t]{2}{*}{ Partial adaptation with practicum resources } & information provision by other participants in practicum \\
\hline & familiarization with psychiatric wards \\
\hline \multirow[t]{2}{*}{ Facing the reconsideration of students' own communication skills } & awareness of insufficient communication skills \\
\hline & communication different from 'usual' one \\
\hline \multirow[t]{2}{*}{ Redefining communication } & return to 'usual' communication \\
\hline & success of strategic communication. \\
\hline \multirow[t]{4}{*}{ Confusion in knowledge about people with mental illness } & difficulty in understanding mental illness \\
\hline & instinctive understanding of mental illness \\
\hline & difficulty in finding problems related to mental illness \\
\hline & difficulty in understanding recovery \\
\hline \multirow[t]{3}{*}{ Difficulty in understanding practical skills in PMHN } & A sense of embarrassment because nursing skills cannot be seen \\
\hline & Awareness of the unavailability of practice templates \\
\hline & Awareness of the inapplicability of simplified expertise \\
\hline \multirow[t]{3}{*}{ Developmental self-learning } & Developmental postponement of questions in practicums \\
\hline & Diversion of experience in practicums \\
\hline & multifaceted understanding of mental illness \\
\hline \multirow[t]{2}{*}{ Non-discovery of significance of practicums } & Giving up on achievements of practicums \\
\hline & drifting questions in practicums \\
\hline
\end{tabular}

\section{Categories}

Formation of learning attitude based on life experience

This category denotes the formation of motivation composed of following four concepts: "evoking interest with visual teaching materials;" "formation of learning motivation dependent on individual's interest;" "motivation based on everyday interest;" and "motivation based on experience with close relationship with mental illness," representing the starting point of learning process. Students' motivation for lectures were formed before the lecture in certain cases through daily life and experiences seeing or hearing about illness or disabilities of someone close to them or were formed through the lecture in certain other cases. Moreover, the formation of motivation among students was highly individualized; motivation for PMHN did not increase in certain students because they compared PMHN with perioperative nursing and nursing for physical illnesses. Furthermore, visual teaching materials using, for example, familiar variety programs and dramas, tended to be beneficial in helping to motivate such students. 
another student's. (omitted) To me, this difference seems to be bigger than the difference in feeling that students have when reading a piece of writing in Japanese (classes) in which emotions represent a subject of teaching. I felt strongly that the difference was attributed to something like each individual's previous experience.

Encounters with ambiguity in PMHN

This category comprised the following two concepts: "anxiety when no answer is presented" and "difficulty in developing concrete image of lecture knowledge." This shows that students themselves see ambiguity in PMHN because an image of knowledge about PMHN is difficult to have based on their own experience and model answers about PMHN skills, such as communication, are not presented to them. While this ambiguity promoted students' "acquisition of superficial knowledge about PMHN" in certain cases, this served as a positive motivation in certain other cases in the form of selfquestioning.

There are many things like "do this when this happens" and "do this for this disease." However, what are we supposed to do when the patient has delusions? Because it is about what the patient is thinking, I thought it requires to have a rich imagination or really it requires the ability to think.

Self-developmental knowledge acquisition

This category represents active learning composed of the following two concepts: "updating existing knowledge with lecture knowledge" and "promotion of understanding through development of images." Because this approach of learning is associated with students' own experience and interests, it helped retention of what was learnt as their own knowledge. Moreover, this independent learning experience promoted an attitude oriented at active understanding in practicums.

I feel like something deep in my memories, similar to a mystery, has been solved by studying this topic. For example, that old man and old woman who had alcohol dependence, now I can understand that, well, they had alcohol dependence, well, I can in retrospect.

Acquisition of superficial knowledge about PMHN

This category comprised the following three concepts: "acquisition of simplified expertise," "increased prejudice because of lecture knowledge," and "acquisition of knowledge for written examination." This denotes passive and superficial learning, which is in contrast with the above-mentioned "selfdevelopmental knowledge acquisition." Superficial learning indicates theories and skills of PMHN received exactly as explained in textbooks or by teachers without questioning. Students were aware of their inflexibility in interpretation in practicums as follows.

I do not feel comfortable with saying 'yes' easily or saying 'no.' Well, denial or affirmation does not seem to be very appropriate in psychiatric classes. I was hearing what the teacher said with such an attitude, so I did not know what the correct answer was, and all I could do was nod my head.

Moreover, superficial understanding represented by this category can increase anxiety and fear about people with mental illness depending contents of lectures, and students with superficial understanding forget contents of lectures after examinations.

A feeling of unrest evoked by the start of practicum

This category represents a feeling of unrest evoked by the start of PMHN practicum, composed of the following three concepts: "a feeling of anxiety from negative image of psychiatric wards," "a feeling of tension evoked by entering a psychiatric ward" due to the environment of the psychiatric ward, and " a mental burden from patient's narrative for understanding a patient " due to having contact with patients in psychiatric wards. In certain cases, a "negative image of the psychiatric ward" was created through lectures. Moreover, these feelings of unrest were described as a common experience of students.

Partial adaptation with practicum resources

This category represents a condition where the abovementioned feeling of unrest is alleviated, composed of the following two concepts: "information provision by other participants in practicums" and "familiarization with psychiatric wards" in terms of both environmental aspect and patient care. Other participants in practicums included other students, instructors, and faculty members. Information was primarily shared among students and advice about communication accounted for a majority of information from faculty members and instructors. This experience affected the direction in the redefinition of communication.

I learnt, about communication for example, that I made a mistake, and I should have communicated with that patient in this manner. I had something like 'eureka!' when I reflected on the practicum at the end together (with instructors).

Facing the reconsideration of students' own communication skills

This category comprised the following two concepts: "awareness of insufficient communication skills" and "communication different from 'usual' one." The former is an experience that students met people with mental illness and thereby noticed their current communication skills were not enough in clinical setting and oriented themselves toward skill improvements. The latter was different in that students did not have the sense of personal transformation, while they experienced a sense of "unusualness" in the PMHN practicum.

It was very difficult to know what response was best for that person. In particular, because a person with mental illness probably, well, his/her mental equilibrium shifts to left and right, I felt that it is difficult to know where the balance is now at the first quick visit.

Page 6/11 
Redefining communication

This category comprised the following two concepts: "return to 'usual' communication" and "success of strategic communication." It represents a reaction of students to "requests to review communication." Similarly to the preceding category, the two concepts were confrontational. The former indicates that a feeling of strangeness caused by communication with people with mental illness is resolved and previous communication is applied.

In the medical records, it said something like bipolar disorder but there was no special remark so I did not consider it to be particularly negative. I didn't consider it that way, in a usual neutral condition, well, when talking...

The latter indicates that students intentionally used professional communication skills and reported new ways of communication.

I have learnt mostly (in classes), something like silence, acceptance, and iteration. They dis summarization and what not, I felt them closer like, oh, that's right...

Confusion in knowledge about people with mental illness

This category, which was composed of four concepts, indicates that students become aware that superficial understanding of lecture knowledge is not sufficient to understand phenomena and situations occurring in practicums. "Difficulty in understanding mental illness" indicates that they cannot understand mental illness they encounter during the practicum, and "instinctive understanding of mental illness" indicates that students can understand that the situation arises from mental illness but they cannot explain how. "Difficulty in finding problems related to mental illness" and "difficulty in understanding recovery" are difficulties related to development of the nursing process. The former is related to problem finding; however, the latter is difficulty in goal setting unique to PMHN.

Difficulty in understanding practical skills in PMHN

This category, which is composed of three concepts, represents difficulties associated with skills that students provide patients during the practicum. "A sense of embarrassment because nursing skills cannot be seen" was attributable to difficulty in visually understanding nursing skills used in psychiatric wards, many of which are not medical procedures. "Awareness of the unavailability of practice templates "denotes the difficulty in seeing the flow of systematic nursing skill, such as clinical pathways, and students told that comparison with other practicums helped to make the flow clear.

In cases of surgery for example, or something for which a template is available, a standard theory has already been established, so it is made into a template, but feelings of people are not understandable...

The "Awareness of the inapplicability of simplified expertise " was attributable to the superficial understanding of expertise in clinical settings involving complex factors concomitantly. Moreover, such difficulty in understanding motivated some students. As in the following narrative, there were certain students who wanted to understand it because they did not know it.

I have not found the answer yet, not at all, so I am just interested in it now, really. It is just an interest. Well, it is what I want to know.

In this narrative about a question that occurred to the student during the practicum, the student distinguished "interest" from formal learning but stated that it was at this point that sustained curiosity arose.

Developmental self-learning

This category, which comprised three concepts, represents positive outcomes of practicums. "Developmental postponement of questions" is acquisition of intention to continue thinking, "Diversion of experience in practicums" is to divert learning outcomes of practicums to everyday life, and "multifaceted understanding of mental illness" is to feel the diversity of people with mental illness, including their strengths. Both of these were associated with awareness of personal transformation.

I might not have been able to find this before. I was thinking about a situation (omitted) in which the patient was speaking to themselves for a long time, and I was wondering to whom the patient was talking: then the patient looked at the space next to him/her and talking as if someone was really there; well, nobody was there, but people like that are actually just going about their daily lives, and it made me realize that there are all sorts of people in the world...

Non-discovery of significance of practicums

This category comprised two concepts and represents the negative outcomes of practicums. "Giving up on achievements of practicums" and "drifting questions in practicums" indicated that students stopped thinking about improvements in PMHN. The former was a state where students did not actively seek outcomes of practicums.

Seriously, the only actual feeling I got was that I could actually meet someone suffering from psychosis for the first time. Yup. That is all in term of result.

The latter described a state in which a student became aware of questions and issues during practicums but stopped thinking about additional improvements. 
It is true that there are people of different ages; therefore, I understand that variation in care are needed to suit each of them, but I think it is impossible to divide patients so precisely in that environment. To me, staff looked too busy taking care of their existing patients. I did not see much leeway left at all so I do not think it would be possible to divide the program further.

\section{Discussion}

A major characteristic of learning in PMHN is that the core knowledge and skills are primarily based on communication and are more abstractive than those used in other clinical departments. Therefore, students' ability to understand abstractive contents, which are unique to PMHN, significantly affected how they received their own achievements in practicums. Previously, studies reported that education in PMHN requires improvements in terms of both quantity and quality for improved understanding of knowledge and practice unique to PMHN by students (22). For example, studies demonstrated that qualitative and quantitative improvements in PMHN education had a positive effect on psychiatry-oriented career choice in nursing students and that nursing students' knowledge significantly correlated with the quality of PMHN education $(23,24)$. This study showed that the background of each student was a major determinant of interest in PMHN and had a persistent effect on practicums. In discussion, some factors responsible for differences in levels of understanding and interest among students were considered.

First, the quantity of PMHN education is examined. A study in nursing education facilities in Australia has reported a large variability in the amount of time allocated for PMHN education (25). The variability between facilities in Japan is unlikely to be as large as in Australia because there are guidelines on how much portion of the curriculum should be allocated for PMHN. Furthermore, this indicates that time allocation to enhance PMHN education is difficult, and a body of evidence on the relationship between the quantity of PMHN education and students' understanding and interest levels should be built for policy recommendations. Moreover, it is necessary to examine measures to improve the quality of practicums and lectures in PMHN in Japan. Graham et al. argued that PMHN involves a broad range of expertise in the field of psychiatry and the requirement to acquire that range of expertise is a unique characteristic of PMHN (26). It has been reported that faculty members feel that they have too little teaching time and human and other resources for practical training, including faculty members, instructors, and facilities, to acquire such comprehensive knowledge and skills and in the field of PMHN in Japan (27). Further educational improvements are required to promote nursing students' understanding and interest with limited resources, and multiple recent studies demonstrated the effectiveness of simulation in the field of PMHN (28-30). In Japan, while simulation-based education is being increasingly introduced in nursing education, there are various issues to be solved, including education system-related problems, such as the training of instructors and establishment of assessment methods, and the budget availability for the realization of small-group education. Diversity may be brought to PMHN education in Japan while solving the education cost problems by building a system for introduction and sharing of PMHN education resources designed based on evidence accumulated by teachers and researchers. This study demonstrated that nursing students' ability to link abstractive knowledge and skills unique to PMHN with their own experiences had a major effect on learning outcomes. The motivation for PMHN was largely improved when lectures were linked with students' personal life experience or previous experience of interacting with someone close to them with mental illness and was maintained during practicums. Furthermore, nursing students failed to make this association during lectures tended to foreground negative outcomes of practicums. A previous study has reported that the satisfaction of practicums improved when time to prepare for practicums was available (23). Given the perspective of the association of PMHN knowledge and skills with nursing students' own experience, which was revealed in this study, the increased amount of preparation for practicums may have served to increase opportunities for nursing students to link their own experiences with the knowledge and skills of PMHN. Furthermore, faculty members and instructors involved in practicums play an important role to allow nursing students to link knowledge and experience. A previous study reported that nursing students' attitudes toward PMHN considerably affect the specialties of faculty members and instructors (31). Furthermore, the attitude toward PMHN has been reported to improve when additional time was spent with instructors during practicums (32). Our results along with the findings of Gough \& Happell suggest that the increased opportunities for instructors and faculty members to attempt the association between students' previous experience and experience during practicums induced attitude improvement. Therefore, faculty members and practicum instructors may be able to induce positive changes in students' levels of interest and attitudes by generating students' interest during the practicum and timely facilitation of the link between the interest and practicum experience. Even for students who are reported not to be PMHN-oriented as per the present results, faculty members and instructors may be able to improve their interest and attitude by intentionally asking and presenting associations between other clinical departments and psychiatry. While our results showed a large impact of students' background on their interest and attitude in PMHN education, the originality of instructors and faculty members was another possible major influencing factor. Because knowledge and skills of PMHN are abstractive, they are practiced in a variety of manners, and nurses are providing patients with care while experiencing uncertainty (10). This uncertainty, which is almost situation-dependent, leaves room for individual nurses to think and make case-by-case decisions in the practice of PMHN. To address these problems, there are important issues remaining to be solved, including construction of an education system and training of educators to see into the character of nurses who practice PMHN and train them as well as clarification of underlying philosophy of practice.

The survey in this study was conducted at one national university in Japan. Because there are variations in both lectures and practicums on PMHN between universities, the effects of such variations should be considered in studies on association between lectures and practicums. Moreover, as we studied only the effects of learning in PMHN that could be perceived by nursing students, it is possible that faculty members and clinical instructors are aware of educational effects that students are not. A more effective education system needs to be constructed after examining the effects of PMHN education as perceived by faculty members and clinical instructors.

\section{Conclusions}


This study demonstrated that the link between lectures and coursework in PMHN education was formed while being significantly affected by life experience and the level of interest of individual nursing students. Our findings suggested that positive the outcomes of practicums are foregrounded when nursing students' own interest is formed during coursework and that otherwise negative outcomes are foregrounded. Therefore, educational support, including coursework and communication strategies that focus on students' experiences and interest and how to deal with uncertainties unique to PMHN practice, needs to be established.

\section{Abbreviations}

PMHN: psychiatric and mental health nursing

M-GTA: modified grounded theory approach

\section{Declarations}

Availability of data and materials

Data available by contacting the corresponding author.

Acknowledgements

We would like to thank all the patients who participated in the study.

Funding

This work was supported by JSPS KAKENHI Grant Number 17K17399

Ethics declarations

Ethics approval and consent to participate

This study was approved by the Yamaguchi University Division of Health Sciences Ethics Committee (Approval no. 529). The participants were informed about the study and assured that the nature of participation was entirely voluntary and that the collected data would be anonymous. Moreover, they were informed that they could withdraw at any time or refuse to have their data used in the research even after interviews had been completed. The Written and informed consent was obtained from all the participants and all participants were over 18 years old. This research was carried out in accordance with the principles of the Helsinki Declaration.

Consent for publication

Not Applicable.

Competing interests

The authors declare there is no financial and non-financial conflict of interests.

Authors' contributions

All author made the designing of study, RO participated in data collection, and data analyzed by RO, HY and KA. The final report and article were written by $\mathrm{RO}$, and were read and approved by all the authors.

\section{References}

1. Saito S. Current status and future prospects of nursing education in Japan. Folia Pharmacol Jpn. 2018;151:186-90.

2. Ministry of Health L and W. Survey on the Enrollment Status and Graduates Employment Status of Nursing Schools. https://www.e-stat.go.jp/statsearch/files?

page=1\&layout $=$ datalist $\&$ toukei $=00450141 \&$ tstat $=000001022606 \&$ cycle $=8 \& y e a r=20191 \&$ month $=0 \&$ tclass $1=000001134383 \&$ tclass $2=000001134404$. 2019.

3. Hislop S, Inglis B, Cope P, Stoddart B, Mclntosh C. Situating theory in practice: student views of theory-practice in Project 2000 nursing programmes. J Adv Nurs. 1996;23(1):171-7. http://doi.wiley.com/10.1111/j.1365-2648.1996.tb03149.x

4. Meyer T, Xu Y. Academic and clinical dissonance in nursing education: are we guilty of failure to rescue? Nurse Educ. 2005;30(2):76-9.

5. Norman L, Buerhaus PI, Donelan K, McCloskey B, Dittus R. Nursing Students Assess Nursing Education. J Prof Nurs. 2005;21(3):150-8. https://www.sciencedirect.com/science/article/pii/S8755722305000529?via\%3Dihub

6. Benner P, Sutphen M, Leonard V, Day L. Educating Nurses: A Call for Radical Transformation. San Fransico, CA: John Wiley \& Sons, Ltd; 2010.288 p.

7. Honda Y. A Professional Significance of Education: Connecting Young People, Schools, and Society. Tokyo: Chikumasyobou; 2009. 224 p.

Page 9/11 
8. Kagawa S, Moro Y. Student Nurses' Experiencing and Construction of “Heterochrony”: Learning Process in the Classroom-Practicum Transition. Japanese J Educ Psychol. 2006;54:346-60.

9. Kagawa S. Texts' "Third Meaning” Developed by Student Nurses Through Boundary-Crossing and the Conflict Between Their Classroom Learning and Clinical Practicum. Japanese J Educ Psychol. 2012;60:167-85.

10. Cutcliffe JR, McKenna HP. Generic nurses: the nemesisi of psychiotric/mental health nursing? In: Cutcliffe JR, Ward MF, editors. Key debates in psychiatric/mental health nursing. Philadelphia, PA: Elsevier Ltd; 2006. p. 92-106.

11. Hartrick G. Relational capacity: The foundation for interpersonal nursing practice. J Adv Nurs. 1997;26(3):523-8.

12. Demir S, Ercan F. The first clinical practice experiences of psychiatric nursing students: A phenomenological study. Nurse Educ Today. 2018;61(October 2017):146-52.

13. Stuart H. Global mental health Reducing the stigma of mental illness. Glob Ment Heal. 2016;3(e17):1-14. https://doi.org/10.1017/gmh.2016.11

14. Doolen J, Giddings M, Johnson M, Nathan GG de, Badia and LO. An Evaluation of Mental Health Simulation with Standardized Patients. Int J Nurs Educ Scholarsh. 2014;11(1):55-62.

15. Flick U. An Introduction to Qualitative Research. 6th ed. Sage Publications; 2018.

16. Takeshita H. Thoughts on and methods used in M-GTA. In: Ishiyama N, Nakanishi Y, editors. Mechanisms of Cross-Boundary Learning: Communities of Practice and Job Crafting. Newcastle upon Tyne: Cambridge Scholars Publishing; 2019. p. 59-89.

17. Glaser BG, Strauss AL. Awareness of Dying. New Jersey: AldineTransaction; 1965.

18. Kinoshita Y. Modified grounded theory approach. Tokyo; Koubundou; 2007.

19. Allan G. A Note on Interviewing Spouses Together. J Marriage Fam. 1980;42(1):205-10.

20. Racher FE. Using conjoint interviews to research the lived experience of elderly rural couples. Nurse Res. 2003;10(3):60-72.

21. Lincoln YS, Guba EG. Naturalistic Inquiry. Beverly Hills, CA: SAGE Publications; 1985.

22. Barry S, Ward L, Walter R. Exploring Nursing Students' Experiences of Learning Using Phenomenography: A Literature Review. J Nurs Educ. 2017;56(10):591-8.

23. Happell B, Robins A, Gough K. Developing more positive attitudes towards mental health nursing in undergraduate students: Part 1 - Does more theory help? J Psychiatr Ment Health Nurs. 2008;15(6):439-46.

24. Happell B, Platania-Phung C. Mental health placements in a general health setting: No substitute for the real thing! J Clin Nurs. 2012;21(1314):2026-33.

25. McCann T V., Lu S, Berryman C. Mental health literacy of Australian Bachelor of Nursing students: A longitudinal study. J Psychiatr Ment Health Nurs. 2009;16(1):61-7.

26. Graham JM, Waddell C, Pachkowski K, Friesen H. Educating the Educators: Determining the Uniqueness of Psychiatric Nursing Practice to Inform Psychiatric Nurse Education. Issues Ment Health Nurs. 2020;41(5):1-9.

27. Tanimoto C. Contents and Problems in Psychiatric Nursing Education at Nursing Universities. Ishikawa J Nurs. 2015;12:85-92.

28. Booth RG, Scerbo CK, Sinclair B, Hancock M, Reid D, Denomy E. Exploring learning content and knowledge transfer in baccalaureate nursing students using a hybrid mental health practice experience. Nurse Educ Today. 2017;51:57-62. http://dx.doi.org/10.1016/j.nedt.2017.01.006

29. Sarikoc G, Ozcan CT, Elcin M. The impact of using standardized patients in psychiatric cases on the levels of motivation and perceived learning of the nursing students. Nurse Educ Today. 2017;51:15-22. http://dx.doi.org/10.1016/j.nedt.2017.01.001

30. Martin CT, Chanda N. Mental Health Clinical Simulation: Therapeutic Communication. Clin Simul Nurs. 2016;12(6):209-14. http://dx.doi.org/10.1016/j.ecns.2016.02.007

31. Santos V, Paes F, Pereira V, Oscar A-C, Silva AC, Carta MG, et al. The role of positive emotion and contributions of positive psychology in depression treatment: Systematic review. Clin Pract Epidemiol Ment Heal. 2013;9:221-37.

32. Happell B, Gough K. Undergraduate nursing students attitude to mental health nursing: a cluster analysis approach. J Clin Nurs. 2009 Nov;18:315566. http://doi.wiley.com/10.1111/j.1365-2702.2009.02917.x

\section{Figures}


Phase of classrooms

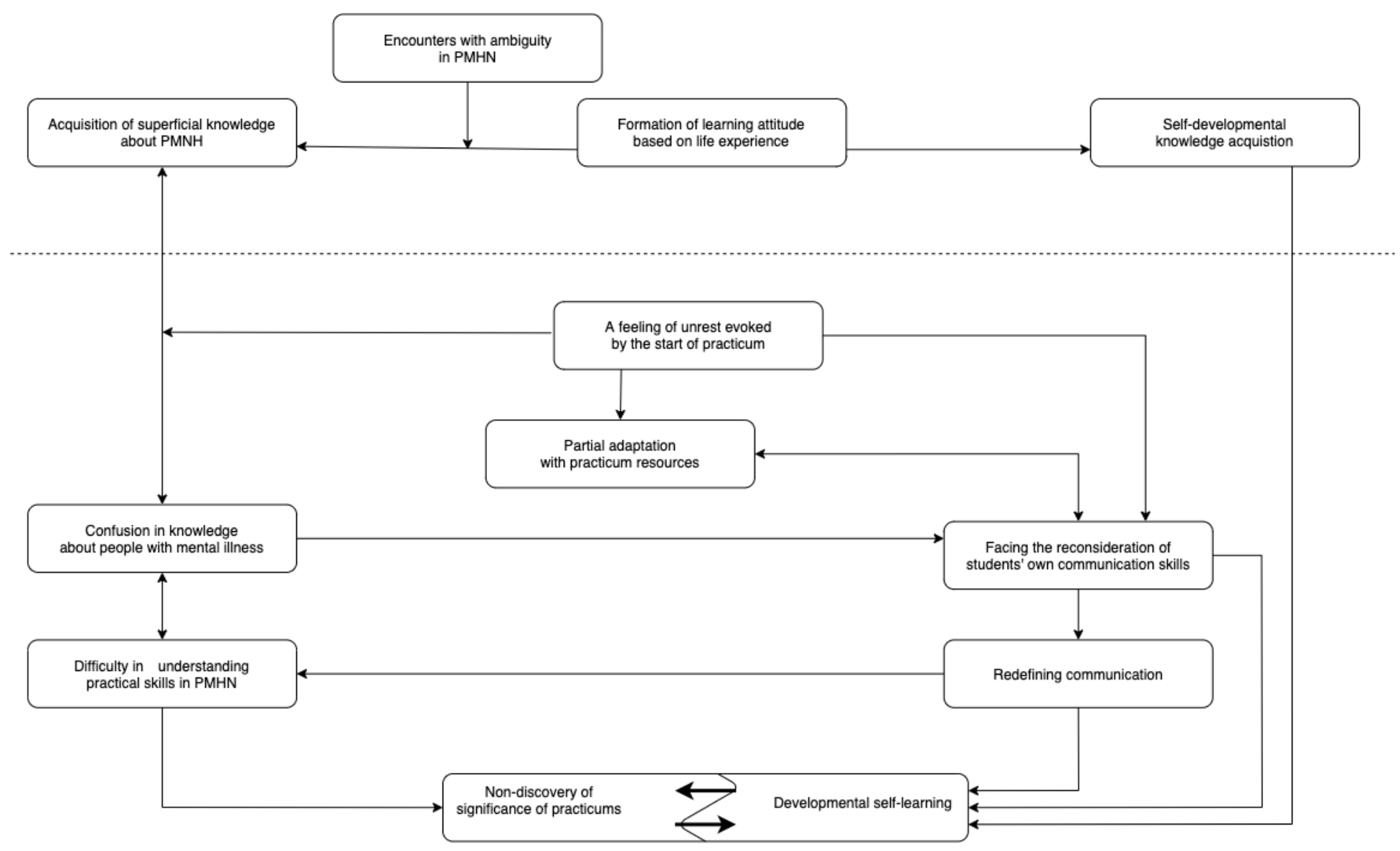

Phase of clinical practice

Figure 1

The relationship between categories 